\title{
Effect of toxigenic Aspergillus flavus and aflatoxins on seed quality parameters of Sorghum bicolor (L.) Moench.
}

\author{
Divakara ST, Aiyaz M, Chandra Nayaka S and Niranjana SR*
}

Department of Studies in Biotechnology, University of Mysore, Mysore-570006, Karnataka, Indiamoonnayak@gmail.com

Divakara ST, Aiyaz M, Chandra Nayaka S, Niranjana SR 2017 - Effect of toxigenic Aspergillus flavus and aflatoxins on seed quality parameters of Sorghum bicolor (L.) Moench. Microbial Biosystems 2(1), 1-8.

\begin{abstract}
The Aspergillus flavus and aflatoxins are known to be detrimental to plant and animals affecting their productivity and yield. This study evaluated effects of toxigenic A. flavus and aflatoxins on physical parameters like seed germination, seedling vigor, root length, shoot length and also biochemical parameters like chlorophyll content, protein, sugars and amylase activity in sorghum seeds. The sorghum seeds were treated with 100,250 and $500 \mu \mathrm{g} \mathrm{ml}^{-1}$ concentrations of aflatoxins and likewise, A. flavus spore suspension adjusted to $1 \times 10^{8}$ spores $\mathrm{ml}^{-1}$ were also treated to seeds in different treatments. The experimental results revealed maximum inhibition of seed germination, seedling vigor, chlorophyll, proteins, total sugars and $\alpha$-amylase activity in the sorghum seedlings was observed at $500 \mu \mathrm{g} \mathrm{ml}^{-1}$ followed by 250 and $100 \mu \mathrm{g} \mathrm{ml}^{-1}$. But seed treatment with toxigenic A. flavus spore suspension showed slight inhibition all the above parameters tested when compared to untreated control, but there was no significant decrease was observed. The study highlighted negative effects of the A. flavus and aflatoxins on the tested seed quality parameters tested there by necessitating need of monitoring of toxigenic fungi and their metabolites in sorghum seeds.
\end{abstract}

Key words - Amylase - Chlorophyll - Great millet - Mycotoxins - Seed germination and Seedling vigour.

\section{Introduction}

Aflatoxins are potent carcinogenic, mutagenic and teratogenic metabolites produced primarily by the fungal species Aspergillus flavus and A. parasiticus. Most of the species of Aspergillus are dominant and play vital role in the seed biodeterioration (Amaike and Keller 2011; Aiyaz et al. 2015). Association of variety of fungi with seeds causes significant loss in seed quality and nutritional quality (Koirala et al. 2005). Fungal organisms play significant role in causing pre- and post-infections and considerable quality losses viz., seed abortion, seed rot, seed necrosis, reduction or elimination of germination capacity, seedling damage and their nutritive value during production, harvest and storage (Mohana et al. 2011; Aiyaz et al. 2015). It is well documented that, mycotoxins produced by specific filamentous fungi and also cause significant reductions in crop yield and economic losses (Bhatnagar and Garcia 2001; Divakara et al. 2015). permits unrestricted use, distribution, and reproduction in any medium, provided the original author and source are credited. 
The involvement of Aspergillus spp. as plant pathogens has not been seriously taken in to consideration, but there is accumulating evidence that the aflatoxins are phytotoxic compounds and secretion in to seeds/ grains interferes with seed germination, seedling growth, protein synthesis, carotenoid, and lipid content in various crops (Sinha and Kumari 1990; Agar and Alposy 2005). The levels of phytohormones such as GA-like substances (GAs), trans-Zeatin ( $t$ $\mathrm{Z}$ ) and indole acetic acid (IAA) have been decreased in the germinating maize seeds exposed to aflatoxin $\mathrm{B}_{1}$ and $\mathrm{G}_{1}$ (Agar et al. 2006).

These toxigenic fungi and aflatoxins were reported as prevalent contaminants of sorghum in India and other parts of the world (Silva et al. 2000; Yassin et al. 2010; Ratnavathi et al. 2012; Divakara et al. 2014). Presently a very few reports are available with respect to their effects on sorghum seed quality parameters. Hence in the present study an attempt has been made to study the effect of these toxigenic fungi and aflatoxins on seed quality parameters of sorghum.

\section{Materials and methods}

\section{Source of sorghum seed samples}

Seeds of sorghum cv. 8340 (Bayer Crop Science) was obtained from the commercial market of Mysore city, Karnataka, India and used throughout the experiments.

\section{Aspergillus flavus}

Toxigenic A. flavus (isolate S3 Accession No. in NCBI-KJ848670, KF309040) was isolated from sorghum seeds and assessed its toxigenicity as described in Divakara et al. (2014) and used for the treatment of sorghum seeds.

\section{Chemicals}

Aflatoxin $\mathrm{B}_{1}$ was purchased from Sigma Aldrich (USA), and initially dissolved in one $\mathrm{ml}$ of Benzene: Acetonitrile (98:2) to make a stock solution of $1 \mathrm{mg} \mathrm{ml}^{-1}$. Further dilutions of aflatoxin $\mathrm{B}_{1}\left(100,250,500 \mu \mathrm{g} \mathrm{ml}^{-1}\right)$ were prepared to treat the sorghum seeds.

\section{Treatment of sorghum seeds with toxigenic $A$. flavus and aflatoxins}

For the treatment of sorghum seeds with toxigenic A. flavus, seven-day-old fresh culture of $A$. flavus was washed with sterile distilled water to obtain the spore suspension and the concentration was adjusted to $1 \times 10^{8}$ spores $\mathrm{ml}^{-1}$ using haemocytometer. To the spore suspension, $0.5 \% \mathrm{CMC}$ was added to facilitate the adherence of spores to seeds and incubated at $25 \pm 2{ }^{\circ} \mathrm{C}$ on a rotary shaker incubator at $150 \mathrm{rpm}$ for $6 \mathrm{~h}$. For the treatment of aflatoxins to sorghum seeds, one hundred sorghum seeds for each treatment were initially soaked in sterile distilled water for one hour and subsequently soaked in different concentrations $\left(100,250\right.$ and $\left.500 \mu \mathrm{g} \mathrm{ml}^{-1}\right)$ of aflatoxin solutions for 24 hours. Control seeds were also soaked in $10 \mathrm{ml}$ sterile distilled water.

\section{Effect of toxigenic $A$. flavus and aflatoxins on seed germination and seedling vigor}

Effect of toxigenic A. flavus and aflatoxins on seed germination was determined by placing the seeds on moist filter papers in Perspex plates and kept for incubation at $25 \pm 2{ }^{\circ} \mathrm{C}$. The germination percentage was determined on the $7^{\text {th }}$ day. Seedling vigor was calculated according to Abdul Baki and Anderson (1973).

\section{Effect of toxigenic $A$. flavus and aflatoxins and on Chlorophyll content in sorghum seedlings}

Chlorophyll (Chl) $a$ and $b$ contents of the newly emerged seedlings were estimated following the method of Arnon (1949). Briefly, the leaves $(0.10 \mathrm{~g})$ were ground with $80 \%$ acetone in a pestle and mortar. The resultant homogenate was centrifuged and the resultant 
supernatant was collected and the absorbance was read at 663 and $645 \mathrm{~nm}$. The amount of chlorophyll $\mathrm{a}$ and $\mathrm{b}$ and total chlorophyll was calculated using the formula mentioned below and expressed as $\mathrm{mg} \mathrm{g}^{-1}$ leaf tissue.

$\mathrm{Chl}_{\mathrm{a}}=[(12.7 \times \mathrm{A} 663) \times(2.6 \times \mathrm{A} 645)] \times \mathrm{ml}$ acetone $/ \mathrm{mg}$ leaf tissue

$\mathrm{Chl}_{\mathrm{b}}=[22.9 \times \mathrm{A} 645) \times(4.68 \times \mathrm{A} 663) \times \mathrm{ml}$ acetone $/ \mathrm{mg}$ leaf tissue

\section{Effect of toxigenic $A$. flavus and aflatoxins on protein and total sugars}

Effects of toxigenic A. flavus and aflatoxins on total proteins, total sugars were determined by following the procedures of Bradford (1976) and Dubois et al. (1956).

\section{Effect of toxigenic $A$. flavus and aflatoxins on $\alpha$-amylase activity}

$\alpha$-amylase activity in the germinating seeds was estimated by the modified method of Kang et al. (1997). Briefly, one g of the germinating seeds were withdrawn from each treatment and grind in $5 \mathrm{ml}$ of pre-chilled $0.05 \mathrm{M}$ citrate buffer, $\mathrm{pH} 6.0$; the resulting homogenate was centrifuged at 10000 r.p.m for 10 min. Enzyme activity was assayed in the supernatant as yield of crude enzyme. To the $0.1 \mathrm{ml}$ of crude enzyme, $0.9 \mathrm{ml}$ of $2 \%$ soluble starch was added and incubated in shaking water bath at $50{ }^{\circ} \mathrm{C}$ for $30 \mathrm{~min}$. The reaction was stopped by adding DNS (Dinitro salicylic acid) reagent and boiled for at least $3 \mathrm{~min}$ for color development. Absorbance was read at $550 \mathrm{~nm}$ against blank. The blank contained all the assay reagents without the enzyme. Standard glucose curve was prepared from glucose concentrations of ranging from 0.0 to $1 \mathrm{mg} \mathrm{ml}^{-1}$ and expressed as release of reducing sugars $\mathrm{g} \mathrm{kg}^{-1}$.

\section{Results}

\section{Effect of toxigenic $A$. flavus and aflatoxins on seed germination and seedling vigor}

The results of the effect of toxigenic A. flavus and aflatoxins on seed germination and seedling vigor are shown in Fig. 1. Seed germination, seedling vigor, root length and shoot length were significantly decreased linearly with increased concentration of aflatoxins over untreated control. Maximum inhibition in seed germination, seedling vigor, root length and shoot length was caused by $500 \mu \mathrm{g} \mathrm{ml}^{-1}$ of aflatoxins treatment when compared to other two treatments $\left(100 \mu \mathrm{g} \mathrm{ml}^{-1}\right.$ and $\left.250 \mu \mathrm{g} \mathrm{ml}^{-1}\right)$. But, treatment of toxigenic A. flavus spore suspension slightly inhibited the germination, seedling vigor, root length and shoot length when compared to untreated control, but there was no significant decrease was observed.

\section{Effect of toxigenic $A$. flavus and aflatoxins on chlorophyll content in sorghum seedlings}

Significant decrease in chlorophyll contents was observed when sorghum seeds were treated with different concentrations of aflatoxins (Fig. 2). Here also marked inhibition of chlorophyll content has been recorded over untreated control and significantly decreased linearly with increased concentration of aflatoxins. Maximum inhibition has been observed at $500 \mu \mathrm{g} \mathrm{ml}^{-}$ ${ }^{1}$ of aflatoxins treatment when compared to other two treatments $\left(100 \mu \mathrm{g} \mathrm{ml}^{-1}\right.$ and $\left.250 \mu \mathrm{g} \mathrm{ml}^{-1}\right)$. There was no significant decrease between control and toxigenic A. flavus spore suspension treatment on the chlorophyll contents of sorghum seedlings.

\section{Effect of toxigenic $A$. flavus and aflatoxins on protein and total sugars}

Studies on the effect of toxigenic A. flavus, aflatoxins on protein and total sugars have showed the significant difference among the control and treatments (Fig. 3). There was a marked decrease in the contents of total proteins and total sugars over untreated control seedlings. Maximum inhibition of has observed at $500 \mu \mathrm{g} \mathrm{ml}^{-1}$ of aflatoxins treatment when compared to other two treatments $\left(100 \mu \mathrm{g} \mathrm{ml}^{-1}\right.$ and $\left.250 \mu \mathrm{g} \mathrm{ml}^{-1}\right)$. There was no significant decrease between 
control and toxigenic A. flavus spore suspension treatment on total sugar contents of sorghum seedlings, but difference was observed in case of protein contents.

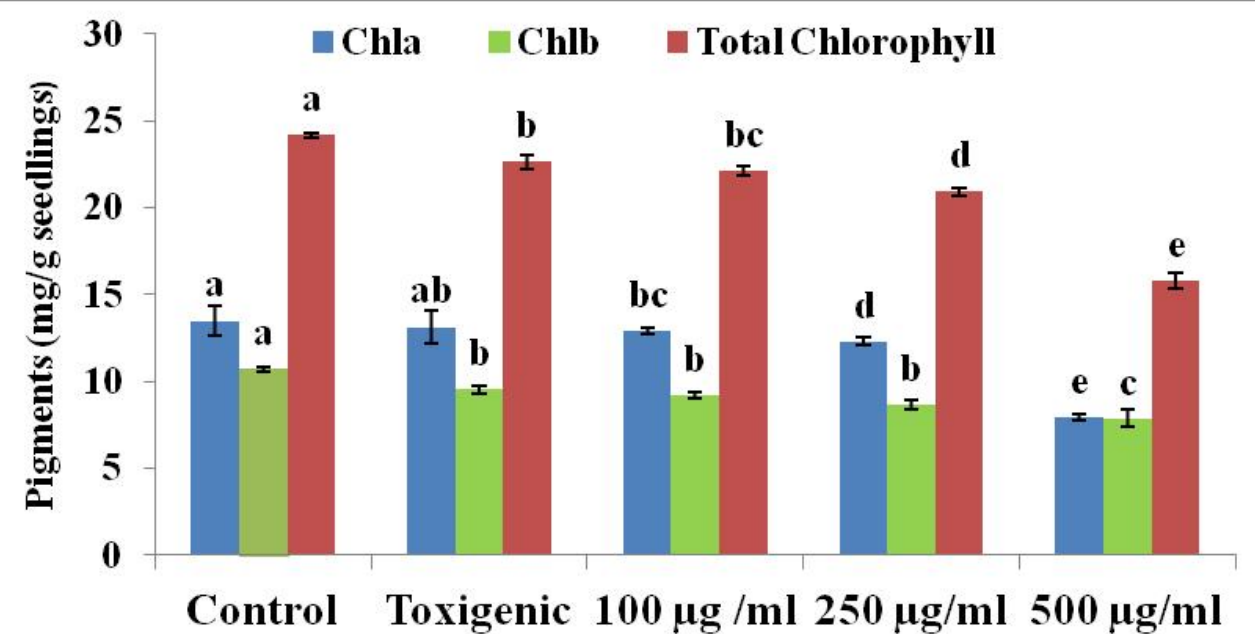

A. flavus

Treatment of sorghum seeds with toxigenic A. flavus and aflatoxins

Fig. 1- Effect of toxigenic A. flavus and aflatoxins at different concentrations on seed germination and seedling vigor. Values are means of four independent replicates. Bars represent standard error.

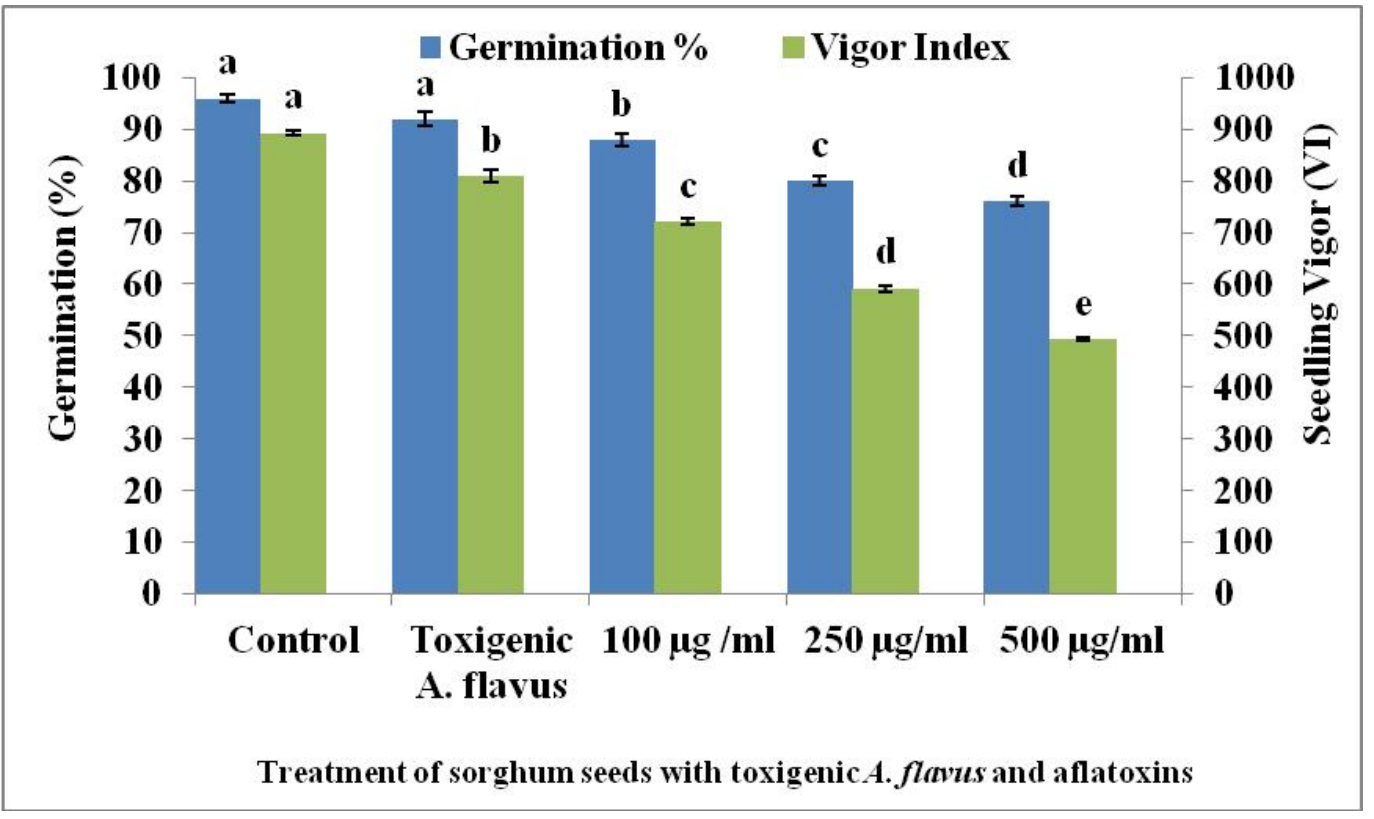

Fig. 2- Effect of toxigenic A. flavus on chlorophyll content in sorghum seedlings. Values are the means of four independent replicates. Bars represent standard error. 


\section{Effect of toxigenic $A$. flavus and aflatoxins on $\alpha$-amylase activity}

The results of the effect of toxigenic A. flavus and aflatoxins on $\alpha$-amylase activity are shown in Fig. 4. $\alpha$-amylase activity in sorghum seedlings has been decreased significantly with linear increase in the concentration of aflatoxin treatment when compared to untreated control. Maximum inhibition was observed at $500 \mu \mathrm{g} \mathrm{m} \mathrm{m}^{-1}$ of aflatoxins treatment when compared to other two treatments $\left(100 \mu \mathrm{g} \mathrm{ml}^{-1}\right.$ and $\left.250 \mu \mathrm{g} \mathrm{ml}^{-1}\right)$. Only slight difference was observed with toxigenic A. flavus treatment when compared to other treatments.

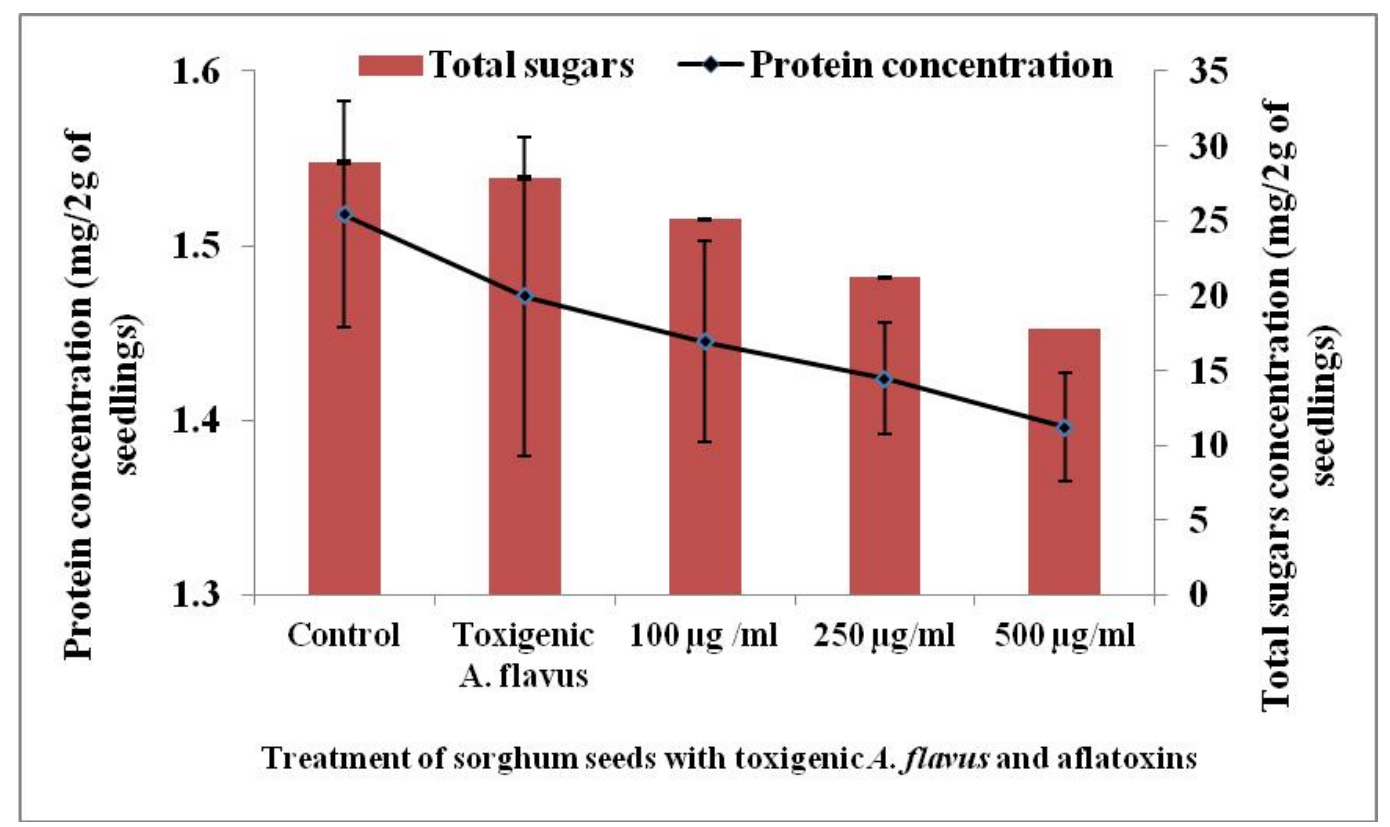

Fig. 3- Effect of toxigenic A. flavus on proteins content and total sugars in sorghum seedlings.

Values are the means of four independent replicates. Bars represent standard error.

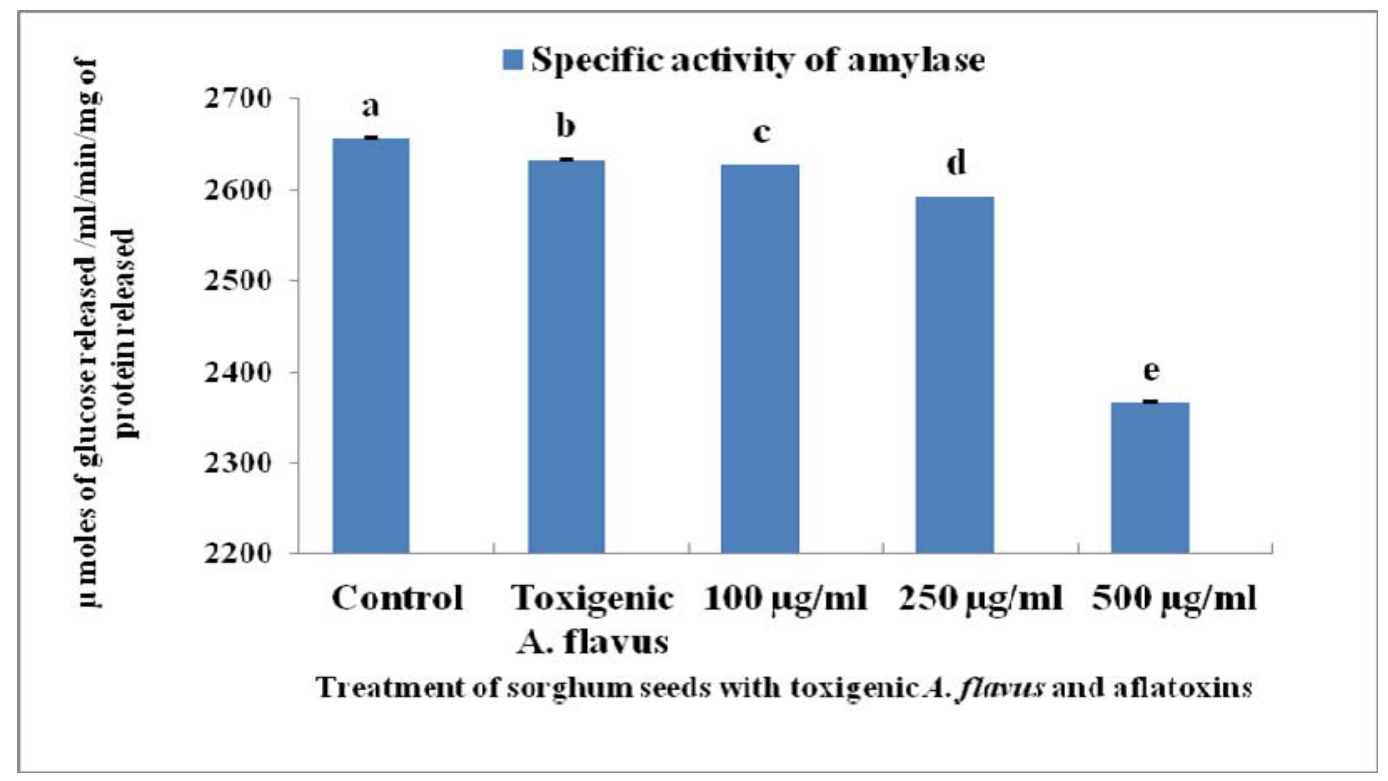


Fig. 4- Effect of toxigenic A. flavus on $\alpha$-amylase activity in sorghum seedlings. Values are the means of four independent replicates. Bars represent standard error.

\section{Discussion}

In the present study, an attempt has been made to study the effect of toxigenic A. flavus and different concentrations of aflatoxins on seed quality parameters of sorghum have been evaluated. It is well known that, contamination of any seed/grain with toxigenic A. flavus and all four types of aflatoxins have toxic effect on living organisms (Shi et al. 1994). Inhibition of seed germination and seedling growth by aflatoxin $\mathrm{B}_{1}$ has been studied earlier in other crop plants (Janardhan et al. 2011; Navya et al. 2013; Divakara et al. 2015). Seed germination and seedling vigor of sorghum was greatly reduced with the treatment of different concentrations of aflatoxins. Maximum inhibition was recorded at $500 \mu \mathrm{g} \mathrm{ml}^{-1}$. Seed germination and seedling growth of maize and broad bean has also been reduced with higher concentrations of aflatoxins (El-Naghy et al. 1999). Similarly, Yaqub Bhat \& Fazal (2011) have studied the effect of A. flavus metabolites on wheat seed germination and seedling development and reported that the higher concentration of culture filtrate obtained from A. flavus reduced the seed germination, root and shoot lengths.

Aflatoxins have been reported to inhibit chlorophyll synthesis in maize plants (Prasad et al. 1996). Marked decrease in the chlorophyll content was observed in the present study are in agreement with the previous results. Inhibition of chlorophyll-a, chlorophyll-b and total chlorophyll content in maize seedlings has been reported (Shirurkar and Nilima 2012). Protein and total sugar contents in the treatments were greatly reduced with increased concentrations of aflatoxins. Decrease in protein contents by aflatoxin has been observed in the germinating maize seeds has been reported (El-Naghy et al. 1999). Changes in starch and sugar contents might be connected with the inhibition of $\alpha$-amylase activity. Harris (1976) correlated the degradation of starch with the activation of starch hydrolyzing enzymes like $\alpha$-amylase during seed germination, which converts the starch molecules in to simple sugars. Because of the reduction in $\alpha$-amylase activity, lower levels of sugars have been observed in the treated seeds. In the present study, $\alpha$-amylase activity has also been reduced greatly with the increased concentration of aflatoxins and maximum inhibition was observed at $500 \mu \mathrm{g} \mathrm{ml}^{-1}$. In pea, transient changes in $\alpha$-amylase activity were correlated with the changes in the rate of starch hydrolysis (Morohashi et al. 1989). Lower contents of sugars in high toxin treated seeds also suggest the least participation of this enzyme and have been reported earlier in maize seedlings (Prasad 1998).

Treatment of sorghum seeds with toxigenic A. flavus on seed quality parameters did not yield significant differences when compared to untreated control. But only slight differences have been observed. This is because of the usage of fresh seeds and A. flavus needs a storage period for establishment in seeds and to produce detectable differences in the seed quality parameters (McDonald and Harkness 1964, 1967). In conclusion, seeds selected for sowing should be devoid of any aflatoxin contamination to reduce the toxic effects on plant growth and development.

\section{Acknowledgements}

The authors are grateful to the Department of Biotechnology (DBT), Govt. of India, (Project- BT/PR9864/AGR/05/391/2007 Dated: 6-6-2008) for the financial support through major research project. The first author also wishes to thank Mr. Wilfred, Senior Research Fellow, Department of Biochemistry, Central Food Technological Research Institute (CFTRI), Mysore and The Chairman, DOS in Biotechnology, University of Mysore and two anonymous reviewers of the manuscript.

\section{Conflict of Interest}

The authors do not have any conflicts of interest. 


\section{References}

Abdul Baki A. A. and Anderson J. D. 1973. Vigor determination in soybean seeds by multiple criteria. Crop Science 13: 630-633.

Agar G. and Alposy L. 2005. Antagonistic effect of selenium against aflatoxin G1 toxicity induced chromosomal aberrations and metabolic activities of two crop plants. Botanical Bulletin of Academia Sinica 64: 301-305.

Agar G., Turker M., Battal P. and Erez M. E. 2006. Phytohormone levels in germinating maize seeds of Zea mays L. exposed to selenium and aflatoxins. Ecotoxicology 15: 443-450.

Aiyaz M., Divakara S. T., Nayaka S. C. and Niranjana S. R. 2015. Efficacy of seed hydropriming with phytoextracts on plant growth promotion and antifungal activity in maize. International Journal of Pest Management 61: 153-160.

Aiyaz M., Divakara S. T., Nayaka S. C., Hariprasad P. and Niranjana S. R. 2015. Application of beneficial rhizospheric microbes for the mitigation of seed-borne mycotoxigenic fungal infection and mycotoxins in maize. Biocontrol Science and Technology, 25: 1105-1119

Amaike S. and Keller N. P. 2011. Aspergillus flavus. Annual Reviews of Phytopathology 49: 107-133.

Arnon D. I. 1949. Copper enzymes in isolated chloroplasts. Polyphenol oxidase in Beta vulgaris. Plant Physiology 24: 1-15.

Bhatnagar D. and Garcia S. 2001. Aspergillus. In: Labbe, R. G and Garcia, S. (Eds.), Guide to food borne pathogens. John Wiley and Sons, New York, pp 35-49.

Bradford M. M. 1976. A rapid and sensitive method for the quantitation of microgram quantities of protein utilizing the principle of protein-dye binding. Annals of Biochemistry 72: 248254.

Divakara S. T., Santosh M., Aiyaz M., Ramana M. V., Hariprasad P., Chandra Nayaka S. and Niranjana S. R. 2013. Molecular identification and characterization of Fusarium spp., associated with sorghum seeds. Journal of Science of Food and Agriculture 94: 11321139.

Divakara S. T., Aiyaz M., Hariprasad P., Nayaka S. C. and Niranjana S. R. 2014. Aspergillus flavus infection and aflatoxin contamination in sorghum seeds and their biological management Archives of Phytopathology and Plant Protection 47: 2141-2156.

Divakara S. T., Aiyaz M., Moore G. G., Venkataramana M., Hariprasad P., Nayaka S. C. and Niranjana S. R. 2015. Analysis of genetic and aflatoxin diversity among Aspergillus flavus isolates collected from sorghum seeds. Journal of Basic Microbiology 55: 12551264.

Dubois M., Gillies K. A., Hamilton J. K., Rebers P. A. and Smith F. 1956. Colorimetric method for the determination sugars and related substances. Annals of Chemistry 28: 350-356.

El-Naghy M. A., Fadl-Allah E. M. and Samhan M. 1999. Effects of aflatoxin G1 on germination, growth and metabolic activities of some crop plants. Cytobiosis 97: 87-93.

Janardhan A., Subramanyam D., Praveen Kumar A., Reddi Pradeep M. and Narashimha G. 2011. Aflatoxin impacts on germinating seeds. Annals of Biological Research 2: 180 188.

Kang G. J., Mo-Joeng K., Jeon-Weon K. and Kwanha P. 1997. Immobilization of thermostable maltogenic amylase from Bacillus stearothermophillus for continuous production of branched oligosaccharide. Journal of Agricultural Food Chemistry 45: 4168-4172.

Koirala P., Kumar S., Yadar B .K. and Premarajan K. C. 2005. Occurrence of aflatoxin in some of the food and feed in Nepal. Indian Journal of Medical Science 59(8): 331-336.

McDonald D. and Harkness C. 1964. Growth of Aspergillus flavus and production of aflatoxin in groundnuts. IV. Tropical Science 6: 12-27.

McDonald D. and Harkness C. 1967. Aflatoxin in the groundnut crop at harvest in northern Nigeria. Tropical Science 9: 148-161. 
Mohana D. C., Prasad P., Veena V. and Raveesha K. A. 2011. Plant extracts effect on seed-borne pathogenic fungi from seeds of paddy grown in southern India. Journal of Plant Protection Research 51(2): 101-106.

Morohashi Y., Kotch H., Kaneko Y. and Matsushima H. 1989. Control of $\alpha$-amylase development in cotyledons during and following germination of mung seed. Plant Physiology 91: 253-258.

Navya H. M., Hariprasad P., Naveen J., Chandra Nayaka S. and Niranjana S. R. 2013. Natural occurrence of aflatoxin, aflatoxigenic and nonaflatoxigenic Aspergillus flavus in groundnut seeds across India. African Journal of Biotechnology 12: 2587-2597.

Prasad G. 1997/98. Combined effects of aflatoxin $B_{1}$ and citrinin on maize seedlings. Biologia Plantarum 40: 441-447.

Prasad G., Sinha K. K. and Ali M. M. 1996. Effect of aflatoxin B1 on chlorophyll, nucleic acid and protein contents in maize. Biologia Plantarum 38(1): 47-50.

Ratnavathi C. V., Komala V. V., Kumar B. S., Das I. K. and Patil J. V. 2012. Natural occurrence of aflatoxin $\mathrm{B}_{1}$ in sorghum grown in different geographical regions of India. Journal of the Science of Food and Agriculture 92: 2416-2420.

Shi C. Y., Chua S. C., Lee H. P. and Ong C. N. 1994. Inhibition of aflatoxin B1 binding and adduct formation by selenium in rats. Cancer Letters 82: 203-208.

Shirurkar D. S. and Nilima K. 2012. Effect of aflatoxin on seed germination and seedling growth. Archives of Applied Sciences Research 4(6): 2441-2446.

Silva J. B., Pozzi C. R., Mallozzi M. A. B., Ortega E .M. and Correa B. 2000. Mycoflora and occurrence of aflatoxin B1 and fumonisin B1 during storage of Brazilian Sorghum. Journal of Agricultural Food Chemistry 48: 4352-4356.

Sinha K. K. and Kumari P. 1990. Some physiological abnormalities induced by aflatoxin B1 in mung seeds (Vigna radiata). Mycopathologia 110: 77-79.

Yaqub Bhat M. and Fazal M. 2011. Effect of Aspergillus flavus metabolites on wheat seed germination and seedling growth. Arab Journal of Plant Protection 29: 139-140.

Yassin M. A., El-Samawaty A. R., Bahkali A., Moslem M., Abd-Elsalam K. A. and Hyde K. D. 2010. Mycotoxin-producing fungi occurring in sorghum grains from Saudi Arabia. Fungal Diversity 44: 45-52. 